\title{
OS CAMPONESES DA REGIÃO DO TRIÂNGULO MINEIRO E A EXPANSÃO DOS AGROCOMBUSTIVEIS. ${ }^{1}$
}

\author{
Rosselvelt José Santos ${ }^{2}$
}

\section{Resumo:}

Entende-se que o conhecimento sobre o campesinato transformou-se e continua sendo construído, tendo sua estruturação discutida e reelaborada a partir do surgimento de novas situações, as quais resultam em debates que fomentam diferentes formas de interpretação e perspectivas de estudo. Realizado com base em pesquisa bibliográfica e empírica, o texto tem, como objetivo, analisar a condição sócio-espacial e cultural dos camponeses da Região do Triângulo Mineiro, estado de Minas Gerais, bem como as suas práticas sociais de (re) existência à expansão dos agrocombustíveis. As formas de produção dos camponeses e a sua possível equivalência, mesmo que aparente, com as formas de produção familiares clássicas ou modernas são analisadas na perspectiva de expor a diversidade de relações sociais e as suas diferentes experiências sócio-espaciais e culturais.

Palavra - chaves: camponeses - cerrado - agrocombustiveis - (re)existência.

\begin{abstract}
:
It is understood that knowledge of the peasantry became and still being built, and its structure discussed and reworked from the emergence of new situations, which result in discussions that encourage different forms of interpretation and study opportunities. Performed based on literature and empirical research, the text aims to analyze the socio-cultural space and the farmers of the Region of Triângulo Mineiro, Minas Gerais state, and their social practices (re)existence of the expansion of agrofuels. The forms of production of farmers and their possible equivalence, even apparent, with the forms of production or modern classic family are examined in light of exposing the diversity of social relationships and their different experiences and socio-cultural space.
\end{abstract}

Key-words: peasants - Cerrado - agrofuels - (re)existence.

\footnotetext{
${ }^{1} \mathrm{O}$ texto tem origem em projeto de pesquisa desenvolvido no Laboratório de Geografia cultural, com financiamento do CNPq e decorre de observações que vem se consolidando a partir de trabalhos de campo sobre o avanço das lavouras de cana-de-açúcar na região do Triângulo Mineiro e a condição territorial das comunidades tradicionais do cerrado. 2 Professor do Instituto de Geografia da Universidade Federal de Uberlândia. Projeto com financiamento do CNPq. E-mail: rosselvelt@ufu.br.
} 


\section{Introdução}

A expansão da cana-de-açúcar, no território nacional, tem sido objeto de importantes debates na sociedade. Abordam-se questões sociais, ambientais, econômicas, sendo que as principais problemáticas envolvem condições de trabalho, presença das comunidades tradicionais, rentabilidade dos processos produtivos, áreas de plantio e sua expansão, degradação do solo, dentre outras.

Além dessas preocupações, penso que existem inquietações teórico-metodológicas entre vários geógrafos, sobretudo com a heterogeneidade das relações de produção no campo brasileiro, bem como a resistência de modos de vida tradicionais. No entanto, não é objetivo deste artigo discutir sobre a teoria norteadora dessas pesquisas, mas considero de enorme importância refletir sobre o desenvolvimento desigual do capitalismo no campo, dos modos de pensar, agir e reagir dos camponeses, em particular daqueles que vivem no Cerrado, cercados pelas grandes lavouras de cana-de-açúcar e das usinas processadoras dessa matériaprima.

Sem dúvida, o processo é amplo e de debate permanente, pois se trata de um espaço engolido por aquilo que o Estado oficializa como sendo desenvolvimento. Isso ocorre porque o capitalismo que aqui se desenvolve está longe de rescindir relações com as diferentes lógicas sociais de produção. A consideração dessas desigualdades não advém de nenhuma descoberta, mas é algo bastante presente na análise de pesquisadores, geógrafos e não geógrafos, no entendimento do capitalismo e do seu processo de produção e reprodução no campo brasileiro.

As reflexões de José de Souza Martins (1975; 1979 e 1980), pesquisador que tratou do desenvolvimento do capitalismo no campo brasileiro, apontam para um processo complexo em que o capital cria relações de produção não especificamente capitalistas, viabilizando a sua expansão em vários setores da economia.

Nessa abordagem, há reconhecimento de toda uma complexidade histórica e sócioespacial das relações sociais de produção, abundantemente presentes em nosso país. Nesta perspectiva e nos objetivos deste trabalho, a reflexão sobre o camponês nos remete à heterogeneidade das experiências de produtores agrícolas e de formas de produzir, que em grande parte estão vinculadas às relações sociais de produção estabelecidas em espaços regionais e locais do território brasileiro. 
No cerrado Mineiro, no contexto da expansão das lavouras de cana-de-açúcar, os empreendimentos capitalistas estão ensejando situações que podem envolver trabalho assalariado, mas também recriando modalidades mistas de dominação capitalista. Aqui, os exemplos são bastante amplos e diversos, e vão desde a produção de cana pela própria usina até a terceirização, a partir da formação de condomínios de fornecedores.

Desse modo, a expansão da cana, na região do Triângulo Mineiro, envolve várias relações sociais de produção. Isso significa que não podemos ignorar essas experiências. Para o Geógrafo, parece-me significativo que ele reconheça a diversidade de relações e nelas a construção de interpretações mais ricas e complexas do espaço agrário e, por conseguinte, do mundo rural.

Como se trata de processos produtivos que afetam produtores tradicionais, precisamos considerar, cada vez mais, esses sujeitos do espaço rural. Essa valorização da diversidade de relações sociais de produção, no espaço, indica uma necessidade de enfrentarmos o cotidiano, a cultura, as práticas sociais e as relações históricas dos produtores com o lugar, como fatores importantes para compreendermos, mais finamente, o campo brasileiro.

O cultivo e a industrialização da cana-de-açúcar, neste momento, envolvem também um importante ator sintagmático; a Usina de álcool e açúcar. Ela atua, no espaço, organizando os processos produtivos e as relações sociais de produção. Esse complexo agroindustrial gera uma série de problemáticas que nem sempre são resolvidas. No que se refere às questões ambientais e sociais, aparentemente, as respostas são construídas e legitimadas no âmbito da legislação existente.

No entanto, o processo de expansão dos agrocombustíveis, em particular a cana-deaçúcar, envolve um movimento de reocupação, redefinição e revalorização dos espaços já ocupados por produtores tradicionais do cerrado, bem como desarticulações de modos de vida fortemente vinculados aos seus respectivos territórios, tornando-se necessários amplos estudos.

A região do Triângulo Mineiro, até o final do século XX, tinha, na criação de gado e cultivo de grãos, a sua principal base econômica. Com a expansão das lavouras de cana-deaçúcar, essa região vai adquirindo novas características, e é neste contexto que o campesinato, como modo de vida, vai sofrer, em seu território, um acelerado processo de desarticulação das relações sociais e de produção.

Nos estudos que venho realizando na região do Triângulo Mineiro, percebo que as paisagens resultantes dos "mares de cana" não eliminaram as unidades de produção camponesa. Trata-se de um produtor que, na relação secular com o cerrado, estabeleceu sua 
produção dentro de um ciclo reprodutivo que se diferencia das demais lavouras comerciais (sobretudo soja e milho) as quais são, em sua grande maioria, produzidas por agentes altamente tecnificados.

Desse modo, a expansão da cana, em áreas já ocupadas, ainda não redefiniu todos os ciclos produtivos e reprodutivos do capital, das pessoas, da natureza e das forças produtivas, inclusive do campesinato. No entanto, independendo das condições socioeconômicas regionais e locais, a simples presença das usinas vai impondo um processo de (re) organização do espaço para extrair dos solos do cerrado, a cana, matéria prima indispensável para produzir álcool, açúcar, energia elétrica, plástico, dentre outros produtos.

Portanto, a cana que existe na região fomenta todo um complexo produtivo que reorganiza, a partir de suas demandas, o espaço e, dentro dele, vai definindo os seus lugares estratégicos, viabilizando os seus fluxos, fixos e mão-de-obra, de forma a atender as expectativas de lucro dos grandes investidores.

Ao final da primeira década do século XXI, o estado de Minas Gerais e, principalmente a região do Triângulo Mineiro, atraiu capitais sucroalcooleiros, cujas previsões do setor apontam para investimentos em novas usinas, até 2010 de US\$ 1,1 bilhão. No Estado, já são 41 usinas, sendo que mais da metade se encontra na região do Triângulo Mineiro. Esse volume de investimento reúne capital nacional e estrangeiro e envolve grupos nordestinos, paulistas, argentinos, franceses, ingleses, norte americano, dentre outros. ${ }^{3}$

Neste artigo, conduzirei a reflexão na perspectiva de expor as condições sociais e técnicas do camponês, na redefinição do espaço e das territorialidades rurais da região do Triângulo Mineiro. O referencial teórico e metodológico, bem como os trabalhos de campo, ajudaram-me a pensar o camponês como um sujeito dinâmico que age sobre as transformações ocorridas no espaço, proporcionando uma existência relativa e relacional à produção dos agrocombustíveis.

\section{Do camponês teórico ao camponês do cerrado do Triângulo Mineiro}

Pensar a problemática da existência, ou mesmo (re) existência camponesa, no entorno dos canaviais da região do Triângulo Mineiro, é, necessariamente, pensar a problemática da sua manutenção relacionada ao modo de produção capitalista. O debate teórico sobre essa

\footnotetext{
${ }^{3}$ Essa associação de capitais vem sendo investigada nos trabalhos de campo, na região do Triângulo Mineiro, desde fevereiro de 2009.
} 
questão é bastante complexo, tal como o é o movimento de produção e reprodução do capital, no processo histórico. Trata-se de produzir uma explicação à manutenção de uma forma de produção que não é capitalista, mas que participa da produção e reprodução do capital seja ele monopolista ou oligopolista.

No interior desse debate apresentam-se alguns caminhos interpretativos da situação atual do campesinato, lançam-se algumas luzes sobre a existência desse produtor. Contudo, são interpretações que revelam conteúdos particulares que, em muitos casos, a partir de tendências da expansão do capital no campo, generalizam situações. Portanto, são caminhos que nem sempre podemos seguir sem desconfiar da sua validade histórica e espacial.

No mundo do capital, o camponês esconde, por trás de sua existência, formas e conteúdos às vezes muito diferentes daqueles que o conhecimento já teorizou. Justamente a análise de realidades históricas concretas é que nos leva a relativizar a validade das teorias que explicam, em determinados momentos históricos e recortes espaciais, a existência, a reprodução e mesmo o desaparecimento do campesinato.

A relação do camponês com o capital é marcada por possibilidades e pelo vir a ser desse produtor familiar. Em síntese, reprodução e eliminação. Perceber, nesse movimento, que o camponês não é uma criatura indiferente às transformações do mundo, significa entendê-lo como sujeito dinâmico de dentro do modo de produção capitalista.

Quando leio sobre o camponês teórico, em algumas obras, devido à profundidade com que se analisou esse produtor familiar, entendo que estou diante de um esforço de treinar o olhar, ver e pensar o real. Esse exercício entre olhar, ver e pensar o real permitiu-me dialogar com a teoria e descobrir, nas minhas pesquisas, na região do Triângulo Mineiro, situações sociais e perspectivas de (re) existência desse camponês.

No conjunto da bibliografia que venho consultando uma reflexão teórica, como se apresenta aqui, tem o objetivo de indicar a contextualidade do debate, no interior do pensamento que me inspirou para introduzir uma interpretação do camponês presente em minhas pesquisas e trabalhar a problemática de sua (re) existência.

Embora tenha me ocupado de reflexões teóricas, em muitos casos um tanto distantes em relação ao tempo e espaço em que me situo, com um estudo sobre a região do Triângulo Mineiro, a questão que se coloca, nesta etapa do trabalho, é, basicamente, discutir de onde deriva, no camponês, a sua resistência, a sua faculdade de se modificar e se adaptar, dinamicamente, sem, contudo, deixar de ser campesinato.

A discussão teórica terá, assim, basicamente, o objetivo de me permitir compreender os termos mais gerais da situação em que se encontram os produtores camponeses e de avaliar 
as relações que eles estabelecem, para se manterem produtivos. Em uma palavra, de iluminar o raciocínio para permitir-me fazer abstrações do concreto e a ele voltar, com mais clareza, com mais poder de interpretá-lo.

Dessa forma, não tenho preocupação em defender um determinado conjunto de ideias ou conceitos. Trata-se, antes, de um esforço para expressar, com conteúdos, a problemática com a qual me defronto.

Inicio a discussão pelo marco referencial elaborado por Karl Kaustky (1968). Na obra "A QUESTÃO AGRÁRIA" 4, o autor apresenta, conjuntamente com as tendências do desenvolvimento do capitalismo no campo, as possibilidades da existência camponesa. Relativamente ao desenvolvimento da agricultura tem-se: a concentração da propriedade, proletarização do campesinato enquanto tal, desenvolvimento da grande exploração em detrimento da pequena, acumulação e centralização de capital na grande exploração (como acontece na indústria), apesar de a agricultura camponesa ser mantida.

Contudo, a existência do campesinato, analisada por Karl Kaustky, creditada de forma direta às privações das satisfações das necessidades domésticas dos familiares e ao excesso de trabalho familiar, coloca-me diante de um tipo de camponês. Abstraindo as condições históricas deste campesinato, penso poder compará-lo, na realidade brasileira nas suas condições atuais, ao produtor camponês tradicional e marginalizado. Ou seja, como categoria social que tem privações e vive basicamente do excesso de trabalho.

No cerrado da região do Triângulo Mineiro esse tipo de camponês parece estar muito próximo do produtor tradicional de leite. Esses produtores tradicionais encontram-se, basicamente nos fundos de vales, nas terras dobradas, onde ainda a grande lavoura, principalmente a da cana-de-açúcar, não chegou.

$\mathrm{Na}$ condição de fornecedor de matéria-prima para os laticínios, como pequeno produtor de leite, visto que seus excedentes, de há muito tempo, despertam interesse do capital agroindustrial, ainda que essa produção seja pequena é uma atividade para produção de renda para a sua família.

Em busca de saídas para garantir geração de renda à família, no cerrado, com a chegada das usinas de álcool e açúcar, há casos em que parte da família buscou emprego nesse setor, procurando conquistar salários e estabilidade.

\footnotetext{
${ }^{4}$ Kaustky, Karl, A questão agrária. Proposta Editorial, São Paulo, 1968.
} 
Essa parte da família - principalmente os filhos mais velhos e em certos casos as mulheres que estudaram - parece saber, desde muito cedo, que a sua reprodução, no interior da unidade familiar, sempre esteve ameaçada.

A gente cresceu dependendo dessas terras e sempre sabendo que era pouco chão, é um pedaço que dá pra faze a despesa de uns (...) difícil é produzir renda pra todos (...). De uns tempo pra cá acho que o arrocho foi maior. Daí o jeito é a gente sai é caça um rumo pra gente (...). ${ }^{5}$

Uma alternativa que se vem constituindo, momentaneamente, para essa mão-de-obra sobrante das famílias camponesas do cerrado, desde a chegada das usinas, sobretudo no início do século XXl, é a de buscar, na proletarização, a possibilidade de reprodução da família, que deixa de ser camponesa.

Obviamente, a proletarização de membros da família camponesa é uma decisão que envolve a própria reprodução da unidade de produção camponesa. Na verdade, a proletarização de uma parte da família acontece quando esse camponês, produtor de leite, vê esgotadas as possibilidades de reproduzir a família, na sua atividade tradicional.

A gente planta o de come (....). Fome ninguém passa, aperto sim (...). Daí a gente leva a vida calculadinho (...) tira um leitinho de umas vaquinhas e faz a renda da despesa (...) não sobra nada (...). Nas águas, a gente tira mais leite pra fazê a renda, pra comer na seca. ${ }^{6}$

Visualizando na existência do campesinato analisado por Karl Kaustky (1968), uma situação clássica, considero que o pequeno produtor de leite do cerrado, que não se tecnificou, apresenta algumas semelhanças. Contudo, neste momento, a situação do produtor familiar camponês que estudo, no cerrado, não é somente daquele que opera sem o emprego de tecnologias. Existem produtores camponeses que, em vários sentidos, são diferentes, principalmente nos aspectos econômicos, psicológicos e tecnológicos.

Quando a gente procura um modo de fazê renda, a gente vai de pouquinho procurando ajuda com quem sabe. Então se a gente sabe produzir leite e vai produzi mais o jeito é encontrar uma orientação de fazê a coisa cresce e fazê mais renda com esse leite. Se a gente tem ordenha mecânica, já diminui o trabalho, se a gente tem um silo, então vai produzir mais na seca, se a gente consegue melhorar a terra o gado pode come melhor e produzir mais (...). ${ }^{7}$

\footnotetext{
${ }^{5}$ Fonte: trabalho de campo na região de Carneirinho, região do Triângulo Mineiro - Fevereiro de 2009.

${ }^{6}$ Fonte: Trabalho de campo na região de Conceição das Alagoas - Triângulo Mineiro - Fevereiro de 2009.

${ }^{7}$ Fonte: Trabalho de campo na região de Veríssimo - Triângulo Mineiro - Fevereiro de 2009.
} 
$\mathrm{Na}$ medida em que esse produtor se projeta no mercado, como liberado das privações tecnológicas, é preciso distinguir, claramente, as particularidades de sua (re)existência. Penso que debitá-las à coação pura e simples do trabalho camponês é tão ingênuo quanto é inexato supor que a sua (re)existência se deva a uma eventual reserva de possibilidades mágicas de sua força de trabalho em suportar jornadas inimagináveis, para resolver as questões mais candentes da vida.

Aqui na propriedade é três pessoa. É pouca gente e o chão também é pequeno, mas se você tem amizade, conhecimento e um jeito de conseguir equipamento com a prefeitura, daí isso ajuda. Então a gente sozinho é um, mas com mais gente, fica mais forte. ${ }^{8}$

Na verdade, nem a manutenção dos padrões de produção camponesa se pode creditar, simplesmente, aos aparatos da força de trabalho, nem as privações desses produtores podem oferecer quaisquer sinais, minimamente confiáveis, que apontem soluções para os camponeses que se encontram mais intimamente premidos pelo capital.

Sem conhecimento, companheiro, equipamento e produto, fica muito difícil toca a vida na roça (...). Então tem que dá um jeito. O equipamento e produto custa muito dinheiro e se a gente não dé um jeitinho com as máquina da prefeitura, a gente fica sem recurso. Então a gente tem que cuidá das coisa e de quem pode empresta as coisa (...). Daí a gente leva tudo no cuidado, na amizade, sem divida (...).sem comprá trem desnecessário (...). É, assim dá pra gente viver (...). ${ }^{9}$

Entendendo que o campesinato, condenado a desaparecer, na interpretação de Karl Kaustky, é do tipo clássico, a manutenção desse produtor desvela uma capacidade de resistência inimaginável de sua força de trabalho, tratada e absolutizada, principalmente, nos estudos da década de 1970. Estudos que, no Brasil, viam a manutenção camponesa como funcional à industrialização do País. Esses produtores, pela sua capacidade de produzir sob qualquer condição, com ou sem lucro, seriam os principais responsáveis pelo barateamento da mão-de-obra urbana ${ }^{10}$.

Uma atenção mais detalhada à obra de Karl Kaustky coloca pelo menos duas questões sobre as condições nas quais esta forma de produção familiar agrícola pode continuar existindo. A primeira, mais de ordem metodológica, alerta para a capacidade revolucionária do capitalismo, mesmo em relação ao campesinato. Aqui se supõe que um decisivo contributo

\footnotetext{
${ }^{8}$ Fonte: Trabalho de campo na região de Capinópolis - Triângulo Mineiro - Março de 2009.

${ }^{9}$ Fonte: Trabalho de campo município de Pirajúba - Triângulo Mineiro - Fevereiro de 2009.

${ }^{10}$ A discussão sobre as interpretações da produção familiar, na década dos 1970, encontra-se em Mauro N.

Barbosa de Almeida. Redescobrindo a família rural. In: Revista de Ciências Sociais n ${ }^{\circ}$ 1, Vol. 1, p. 66-83, 1986
} 
para o entendimento da manutenção camponesa esteja no exame das particularidades com que o capital promove a sua conexão com a pequena exploração, através de sua transformação:

se se deseja estudar a questão agrária segundo o método de Marx, não se deve equacionar apenas o problema de saber se a pequena exploração tem ou não futuro na agricultura. Deve-se ao contrário, pesquisar todas as transformações experimentadas por esta última no decurso do regime de produção capitalista. Devese pesquisar se e como o capital se apodera da agricultura, revolucionando-a, subvertendo as antigas formas de produção e de propriedade, criando a necessidade de novas formas ${ }^{11}$.

A segunda sugestão que me parece indicativa para refletir sobre a manutenção do campesinato no campo refere-se ao movimento da propriedade privada.

Entendendo Kaustky que a existência da pequena e da grande propriedade depende de um jogo entre os rendimentos alcançados em cada uma das diferentes unidades de produção agrícola, esse autor percebe que:

A manutenção do camponês abastado é sobretudo desejável por motivos políticos: é ele e não o pequeno camponês que constitui o baluarte supremo da propriedade privada. Nisto a sua exploração supera bastante a do pequeno cultivador. Mas este último é o melhor fornecedor de braços ${ }^{12}$.

No conjunto das ideias expostas nesta citação, ficam marcadas as diferenças dentro do campesinato, e nelas as formas de existência desses produtores para o modo de produção capitalista. Entre o camponês rico e o pobre o primeiro representa, pela defesa da propriedade privada, a sua própria auto-exploração. Quanto ao segundo, enquanto não desaparece, funciona como uma reserva de força de trabalho residente no campo. ${ }^{13}$

Para compreender melhor a diversidade de situações produzidas pela expansão do capital no campo, em comunidades campesinas, é necessário observar, em Karl Kaustky, que na primeira citação, contemplar a riqueza do real é o primeiro passo. O que significa dizer que a realidade onde se reproduz o camponês é mais rica que qualquer teoria. Em uma palavra, a investigação do campesinato, no real é, sem dúvida, um caminho para não se cair em afirmações vazias sobre a existência ou não de formas de produção campesinas.

Nesta perspectiva, existem diferentes condições, determinadas por diferentes interesses sociais, políticos, econômicos, produtivos e reprodutivos da sociedade, para que o campesinato seja mantido. Redescobrindo-lhe a riqueza e o sentido da sua produção, parece

\footnotetext{
${ }^{11}$ Kaustky, Karl. A questão Agrária. (1968:24).

${ }^{12} \operatorname{Idem}($ p. 185).

${ }^{13}$ Em Limeira do Oeste, município pertencente à região do Triângulo Mineiro, encontrei vários membros de unidades de produção camponesa se proletarizando nas usinas de álcool e açúcar, deixando a propriedade aos cuidados das esposas e filhos.
} 
que o camponês, em cada momento histórico, desenvolve um conjunto de relações ativas relacionadas ao modo de produção dominante que lhe permite, nas transformações do mundo, reproduzir-se, transformando-se.

A gente fica pensando sobre aquilo que a gente era. Nóis vivia pra comê. Não tinha recurso para investi, era assim muito difícil, a gente ficava esperado pelo tempo. Então se chovesse era bom, tudo ia bem, mas se fosse seca braba a gente penava. Hoje você não deixa o bicho morrê sem socorro. Tem gente que não entra no banco de jeito nenhum, mas hoje com orientação a gente pode pega Pronaf e melhorar os recurso pra produzi. ${ }^{14}$

A superação camponesa parece comportar a decadência da sua situação clássica. Compreende, pois, sua realização, ao mesmo tempo que o fim da outra situação. O camponês, pobre ou rico, pertence a um momento histórico. Assim se recupera, na análise do camponês real, a possibilidade de sua racionalidade ser imanente às relações sociais. Não obstante seus conflitos com o modo de produção dominante, ou melhor, em razão desses conflitos, certamente existem os estímulos à resistência e à criatividade camponesa.

\begin{abstract}
A gente reclama do Pronaf, do governo, de muitas coisas (...). Eu acho que tá certo, mas não pode deixá de participa e reclamá. Eu digo que o Pronaf é um recurso (...). Tinha que ser mais recurso, tinha que dá pra fazê uma mudança na produção (...). Se não mudar, a gente vai pra onde (...) assim, com mais recurso, a gente melhora o nosso produto e vai ficando na terra. Então a gente tem que fazê aquilo que dá e luta pra fazê o governo melhora o nosso recurso (....). É ai que eu digo, a gente precisa se uni, usa bem a cabeça, usa bem o recurso e faze as coisa funcioná pro lado da gente $(\ldots) .^{15}$
\end{abstract}

Voltando a Kaustky, entendo que, para este autor, o campesinato pobre é um produtor que não consegue incorporar as transformações impostas pelo desenvolvimento do capitalismo, sendo a sua existência decorrente de sua resistência física. Esse produtor é uma reserva de força de trabalho. Em síntese, essa contribuição aponta para a necessidade de investigação das condições de existência do outro camponês, o camponês abastado que, por questões políticas envolvendo a manutenção da estrutura agrária e a rentabilidade do capital, o qual, para Kaustky, é o melhor equipado; por isso ele o considera de mais fácil subordinação ao capital.

Assim, o conteúdo revelado na análise de Kaustky a que me refiro coloca, além da necessidade de investigar as condições e o sentido da manutenção da produção familiar camponesa, neste momento, as possibilidades de as forças sociais dominantes e do Estado em

\footnotetext{
${ }^{14}$ Fonte: Trabalho de campo município de Tupaciguara - Triângulo Mineiro - Fevereiro de 2009.

${ }^{15}$ Fonte: Trabalho de campo município de Carneirinho - Triângulo Mineiro - Junho de 2009.
} 
recriá-los. Mesmo porque a produção familiar está sendo incluída, de diferentes formas, na reprodução em geral.

Nóis aqui não vai produzir cana, a gente tem lavoura de café que o pai e a mãe levo tempo pra formá. O povo comprô muito equipamento, assim investiu na lavoura (...). Café é de investi recurso, daí ele dá sempre e a gente consegue produzi no `meio' dele, assim entre uma fila e outra. Aqui tem maracujá, milho, abóbora (...). Daí, também não é só café, a gente vai lidando com outras lavoura e com um porquinho, gadinho, galinha a gente vai vivendo (...). Então a renda não é só dali. ${ }^{16}$

Tomando-se como referência de estudo a agricultura brasileira e, mais especificamente, a do Triângulo Mineiro, no quadro em que se reproduz o capital no campo, vê-se que esta apresenta diferenças sócio-econômicas marcantes. A meu ver, essas diferenças possibilitam a configuração de regiões, a partir do estudo da produção familiar camponesa e das formas como esta se relaciona ao grande capital monopolista e oligopolista.

Portanto, antes de apresentar uma interpretação definitiva sobre o produtor camponês, em nosso País, é necessário que se analise e se produza um conteúdo explicativo da presença e expansão do capital no campo e as particularidades com que se realizam essas relações da produção camponesa com o capital.

Notadamente, uma das mais profundas diferenças entre produtores camponeses, nesse processo de transformação tecnológica da agricultura brasileira, está entre aqueles que conseguiram acumular meios de produção e os que saíram para a cidade ou para as terras da Amazônia.

Parece um tanto estranho falar em acumulação de meios de produção em unidades de produção camponesa; para dar sentido a essa acumulação, que visualizo em várias das propriedades camponesas do cerrado mineiro e para que não confundamos produtor familiar com capitalista, pela simples propriedade dos meios de produção, recorro aos pressupostos de Marx, sobre o que é uma relação de capital: "Os meios de produção só se tornam capital na medida que se autonomizam como poder autônomo face ao trabalho" (1956, t.1, p. 477).

Em meio aos canaviais da região do Triângulo Mineiro tenho encontrado diferentes produtores e lógicas sociais de produção. Nesse universo, existem camponeses que utilizam ordenha mecânica, que investem no melhoramento genético do gado, bem como na recuperação das pastagens, mas continuam tendo como base produtiva a família.

Em verdade, o que tenho observado e estudado nessa região são produtores camponeses que tendem a se tornar parte do seu processo produtivo tecnificado. Essa

\footnotetext{
${ }^{16}$ Fonte: Trabalho de campo município de Santa Vitória - Triângulo Mineiro - Fevereiro de 2009.
} 
situação, embora não seja geral, é, em relação à realidade brasileira, uma tendência importante para compreendermos a sua capacidade de inovação e adaptação às imposições do mercado. Utilizando-se eventualmente de força de trabalho assalariada, o trabalho familiar explorado com equipamentos, máquinas e insumos agropecuários tem aumentado as suas capacidades produtivas, assim como as perspectivas de reprodução. São, portanto, donos dos meios de produção e da terra.

Hoje fica muito difícil produzir leite só dando sal pro gado, é preciso fazê uma melhora na alimentação, fazê uns cruzamento com raça boa de leite. Mesmo se você der cana pro bicho, precisa calcário na terra senão fica tudo muito fraco e a produção não vai dá conta da nossa precisão (...). ${ }^{17}$

Os meios de produção, desta forma, são os meios de reprodução camponesa socialmente necessários, e não os mecanismos para se apropriar do trabalho de outrem e, ampliadamente, obter a sua reprodução.

Nesta relação, os meios de produção, na mão do trabalhador camponês, aumentam a capacidade produtiva da força de trabalho familiar, de exploração dos recursos da propriedade, como também as possibilidades de endividamento e, conseqüentemente, subordinação ao sistema financeiro. Trata-se, portanto de alterações na escala da agricultura camponesa imposta pelo capital monopolista e oligopolista.

Contudo, há algumas possibilidades de transformação que as alterações tecnológicas podem produzir na produção camponesa. Mais precisamente, a necessidade tecnológica também é a expressão de outras possibilidades de superação. Apesar de o uso de tecnologia ser, cada vez mais, uma imposição do grande capital, a condição para tecnificar a produção camponesa está relacionada a sua disponibilidade de dinheiro, de crédito e capacidade de se organizar e reivindicar junto ao poder público assistência técnica e serviços que dependem de máquinas e equipamentos muito caros para serem adquiridos individualmente. E para isso, às vezes, a criatividade camponesa produz respostas surpreendentes, que nem sempre endividam o camponês, nem o individualizam.

A gente tem algum equipamento, mas a prefeitura tem o trator. $\mathrm{O}$ silo é uma coisa importante para quem produz leite (...). Mas é preciso que a gente se junte para cobrar da prefeitura as máquinas pra fazer o silo. A gente sozinho fica isolado e não consegue possuí tudo que é "trem"e nem pedi pra prefeitura fazê o serviço pesado $(\ldots) .^{18}$

\footnotetext{
${ }^{17}$ Fonte: Trabalho de campo município de Araguari - Triângulo Mineiro - Abril de 2009.

${ }^{18}$ Fonte: Trabalho de campo município de Campo Florido - Triângulo Mineiro - Agosto de 2009.
} 
Essas colocações sobre o sentido do envolvimento comunitário e acumulação dos meios de produção na produção camponesa precisam ser finamente exploradas. Entendo que a estas, se ligam às transformações do produtor, da produção, da propriedade e dos mecanismos de exploração da forma de produção camponesa. Mais precisamente, com o desenvolvimento tecnológico, das condições de pequenas trocas esse produtor se vê premido pelos oligopólios e monopólios, que lhe determinam as condições de produção. Contraditoriamente, também se vê inserido à racionalidade imanente às relações sociais do modo de produção dominante.

Dessa situação em que se encontra o camponês, principalmente o tecnificado, as reflexões que faço às interpretações que os colocam como burgueses ${ }^{19}$ ou como trabalhadores para o capital $^{20}$ (interpretações que percebem, sob o modo de produção capitalista, como tendência geral à eliminação do camponês), é que o camponês continua camponês, só que, como se encontram em outro momento histórico, sobre outras necessidades, que geram outros comportamentos.

\section{As especificidades do camponês do cerrado}

Pensar as condições de existência do camponês, no cerrado do Triângulo Mineiro, tem me levado a discutir os desencontros sociais, culturais, étnicos e espaciais que resultam das transformações provocadas pelo avanço dos agrocombustíveis, na região. Como parte das problemáticas que aparecem no campo dessa região, o camponês, que muitas das vezes é compelido, pelas grandes lavouras, a viver o estranhamento dos seus próprios territórios, continua organizando a sua vida sob bases territoriais locais.

Desse modo, a condição camponesa remete não apenas à análise de projetos individuais desses produtores tradicionais do cerrado; a compreensão das relações sociais que se estabelecem nos lugares que vão sendo invadidos pelas grandes lavouras de cana coloca, como problemática, o entendimento da existência camponesa.

O camponês que estou analisando é o produtor que, na relação com os agentes institucionalizados (Emater ${ }^{21}$, bancos, cooperativas, associações de produtores, prefeituras, dentre outras), aponta para várias possibilidades de continuar vivendo no cerrado. Uma situação que não aparece apenas como afirmação da identidade camponesa, mas fundamentada nas relações sociais e de produção estabelecidas na família e comunidade.

\footnotetext{
${ }^{19}$ Sandroni, Paulo. A questão Agrária e o Campesinato. A funcionalidade da pequena produção Mercantil. São Paulo. Polis 1980.

${ }^{20}$ Graziano da Silva J. Processo Técnico e Relações de Trabalho na Agricultura, São Paulo, HUCITEC 1981.

21 (Emater-MG) - Empresa de Assistência Técnica e Extensão Rural do Estado de Minas Gerais.
} 
Na perspectiva dos processos de reocupação do cerrado, percebo que tem ocorrido um conjunto de aspectos fortemente ligados entre si e que carregam a marca de importantes conquistas, que incluem o reconhecimento do campesinato, no âmbito das localidades rurais, como pessoas pertencentes a um grupo étnico e cultural. No movimento de reocupação do espaço, essas identidades indicam pertenças, enraizamentos, bem como práticas sociais que estão intimamente ligadas e relacionadas ao modo de vida do camponês dessa parte do cerrado.

Em termos de modo de vida, é importante considerar que tudo isso fica seriamente ameaçado pelos capitais investidos nas Usinas de álcool e açúcar. A sua presença compreende estranhamentos decorrentes das transformações no processo de remoção de valores sócioculturais, embates, consensos e dissensos, pois a presença dessas novas formas de produzir reorganiza o espaço desarticulando os territórios camponeses que, em grande parte, se estruturavam nas relações de vizinhança.

(...) aqui, agora é cana pra todo o lado. Isso é muito triste, faz dó a gente vê o gado sem sombra. O povo não consegue vê quase nada que tinha antes (...) Vê cana, poeira, cinza, caminhão (treminhão), fogo, máquina, gente que a gente nunca viu e vizinho que a gente não vê mais (...). ${ }^{22}$

Essas mudanças são tão significativas que vão tornando complexa e complicada uma representação sócio-espacial que possibilite o reconhecimento territorial, legitimando direitos de um existir camponês, em seus espaços e lugares comunitários.

Como é que a gente vivê? Vivê desse jeito, com cana na nossa porteira, com poeira, fogo e cinza, caminhão que joga a gente pra forra da nossa estrada, máquina que é um mundo e um cheiro de coisa ruim (...). Hoje a gente não tem nem palha de arroz pro gado de leite descansa. Esse povo da usina é poderoso, não quer sabê se é isso ou é aquilo (...) Vai fazendo, não importa. Faz o que acha certo porque dá certo (...). A gente então quer continuar aqui, mas do jeito que vai, fica difícil vivê no nosso lugar. $^{23}$

Em minhas pesquisas, esse produtor, ao ser indagado sobre o desenvolvimento promovido pelas usinas, desconfia do progresso anunciado e denuncia a retirada das árvores, do fogo que pula para a mata, do uso dos agrotóxicos, dentre outros procedimentos produtivos que dificultam a defesa do seu território. Por esse motivo, considero que esse camponês é também uma força política e a sua existência, em localidades territorializadas por práticas sociais historicamente constituídas, pode possibilitar análises importantes do campesinato, do cerrado e das suas influências mútuas.

\footnotetext{
${ }^{22}$ Fonte: Trabalho de campo município de Araporã - Triângulo Mineiro - Agosto de 2009.

${ }^{23}$ Fonte: Trabalho de campo município de Canápolis - Triângulo Mineiro - Agosto de 2009.
} 
Então é assim, o gado precisa de sombra. Se você tira a árvore o gado vai pra onde (...). Como ele vai se protege (...). A gente fica triste, porque não dá pra voltá o gado na área da cana (...). nela tudo foi limpado, assim liquidado. Outra coisa, o gado precisa de água boa, assim, limpinha (...). ${ }^{24}$

Os saberes sobre o cerrado são elaborações historicamente constituídas e é nas comunidades que os conhecimentos foram sendo transmitidos e por vezes modificados. Nesse processo, ocorrem os costumes, as tradições, os hábitos, as práticas sociais para se viver no cerrado e que estão sendo impedidas de se manifestarem, dentro do contexto da expansão dos agrocombustíveis.

Parece que isso aqui não é mais o nosso lugar. Tudo ficou muito diferente, é difícil de explicar pra uma pessoa como chegar num lugar. Antes a gente indicava a casa de um vizinho dizendo quantas fazenda ou casas tinha que passá, quantas porteira tinha que abrir, quantos mata-burro tinha que pulá. Agora não tem nem os pau-d'óleo (árvore) pra indicá. As coisas, rapidinho, vai sumindo e a gente não enxerga solução. ${ }^{25}$

A compreensão do modo de vida dos produtores agrícolas tradicionais do cerrado do Triângulo Mineiro é requisito fundamental para entender as relações com a natureza do cerrado, as suas práticas sociais, bem como os seus desdobramentos na existência camponesa.

(...) quando não tinha cana, tinha mais vizinho, tinha mais terra pra colocá o gado, tinha mais gente na festa, na missa, gente que a gente conhecia, agora aparece gente que a gente não conhece, que a gente nem sabe como chega pra conversa, falá da vida, dessas coisas que a gente sempre fala quando se encontra $(. ..) .^{26}$

Nesta perspectiva, as territorialidades e a sua articulação em termos socioculturais, impõem outras presenças, que se materializam fortemente sob a forma de proposições que anunciam novos usos e apropriações dos recursos existentes no cerrado.

No começo parecia um negócio bom fazê arrendamento... Então, muita gente alugou um pedaço ou tudo que tinha (...) fico assim iludido. Ilusão do dinheiro fácil (...) depois foram vendo que não era bem assim (...) A gente que tem pouco chão não entra nessa. Então o jeito é continuar lidando com as nossas coisas, com um leitinho (...) gadinho e melhorando a renda da gente. ${ }^{27}$

Neste processo, grupos de produtores tradicionais realizaram, nos seus lugares de vivência, interpretações sobre as novas relações trazidas e impostas pelos agrocombustíveis, alias extremamente importantes para compreendermos as suas condições de produção.

\footnotetext{
${ }^{24}$ Fonte: Trabalho de campo município de Frutal - Triângulo Mineiro - Agosto de 2009.

${ }^{25}$ Fonte: Trabalho de campo município de Itapagipe - Triângulo Mineiro - Agosto de 2009.

${ }^{26}$ Fonte: Trabalho de campo município de Araguari - Triângulo Mineiro - Agosto de 2009.

${ }^{27}$ Fonte: Trabalho de campo município de União de Minas - Triângulo Mineiro - Março de 2009.
} 
A gente sempre trabalhou pra leva a vida. Um trabalho pesado. Então muita gente pensou em ganhar a vida de outro modo, assim, mais leve. Acho que isso não é uma coisa ruim. Então ganhar sem fazê nada parecia uma coisa boa. Então, ninguém da usina procura a gente. Em casa a gente viu que a usina se interessa por chão grande. Se a gente não se enquadra o jeito foi continuá com a produção. Daí os menino se interessaram em trabalhar pra a usina. Eles com emprego, ficou mais fácil equilibrar as coisas. $^{28}$

Isso tem possibilitado o surgimento de novas formas de pensar e de agir. Em certos casos, não há o abandono das práticas produtivas, mas uma redução das famílias, bem como uma busca de orientação tecnológica para melhorar os resultados da produção e do existir camponês no lugar e na comunidade.

Aprender as novidades nunca é demais, isso é uma coisa muito certa, mais a gente precisa fazê esse conhecimento virá uma coisa pro futuro (...), aqui o povo participa de curso de inseminação, de produção de queijo, de doce, de ração... Sem dúvida a mulher é mais animada (...). ${ }^{29}$

A força de trabalho feminino, neste caso, é também força política que atua na busca e no reconhecimento da importância de se produzir sob novas orientações tecnológicas. A mulher se liga a um processo de conquista, de divisão do trabalho e também de negociação de usos e apropriações do tempo e do espaço da família do produtor camponês.

O interesse da mulher é de curso que ajude na renda, assim melhorar a vida da família. Então, o curso que a gente pede e eles com condição vem aqui e faz não é pra gente perder tempo (...). Então a associação tem que pedi aquilo que a gente ta precisando. Mas isso é resolvido na reunião (...). Então a gente forma grupo, ele é importante para conseguir as coisas (...). ${ }^{30}$

A comunidade e a família camponesa apresentam um reconhecimento das suas individualidades sociais que aparentemente sempre existiu, mas que não representa, nesse momento, obstáculo para que as orientações tecnológicas cheguem aos lugares.

Em outras situações, a família não está ainda totalmente constituída de capacidade produtiva nas atividades agropecuárias para oferecer aos seus membros e ao mercado os resultados do seu trabalho. Essa afirmação pode despertar desconfiança e mesmo ceticismo. Afinal, os camponeses fazem parte de um mundo onde "o mercado também recria relações sociais tradicionais, além de criar relações igualmente tradicionalizadas. E delas se nutre" (Martins, 1975). Mas, no caso dos camponeses, apesar de contarem com créditos federais e assistência técnica, essa produção depende do trabalho, da comunidade de criatividade camponesa.

\footnotetext{
${ }^{28}$ Fonte: Trabalho de campo município de Iturama - Triângulo Mineiro - Abril de 2009.

${ }^{29}$ Fonte: Trabalho de campo município de Uberaba - Triângulo Mineiro - Agosto de 2009.

${ }^{30}$ Fonte: Trabalho de campo município de Delta - Triângulo Mineiro - Agosto de 2009.
} 
Aqui é importante considerar que os camponeses do Triângulo Mineiro, com a chegada da cana, se diferenciam e estão dissociados da comunidade campesina tradicional. A sua existência e manutenção, na terra, ocorre juntamente com a dissolução de alguns traços da cultura tradicional, mas jamais ocorre a possibilidade de anular ou impossibilitar a organização da comunidade camponesa. Porém, como estou pensando as mudanças tecnológicas e socioespaciais que chegam até o camponês é preciso considerar as formas atuais da sua organização na perspectiva da familia, das associações e da representação desta nos conselhos municipais.

\section{Considerações finais}

Discutir as problemáticas relacionadas aos grupos de produtores tradicionais do cerrado e que assumem, nas suas localidades, uma intrincada luta pela sua manutenção, impõe o reconhecimento das suas diferentes formas de existir e dos desdobramentos destas na

relação com as instituições comunitárias e estatais, bem como com as novas imposições sócioespaciais e tecnológicas.

Neste processo, as familias e associações de produtores camponeses mostram transformações políticas conseqüentes e, aparentemente, constituem uma restauração da comunidade e uma capitulação política dos camponeses. Esta é uma observação importante, que inclui aspectos fundantes da existência camponesa nos entornos das grandes lavouras de cana. Em primeiro lugar, a preponderância das determinações formais na constituição das associações, e conseqüentemente, na organização das comunidades, não garante sociabilidade aos produtores para suportar as imposições da sociedade e do mercado, mas viabiliza envolvimento político dos produtores para conduzir as suas demandas junto aos órgãos competentes do Estado, que se fazem presentes no lugar em que vivem.

Em segundo lugar, o caráter socialmente mediador da associação e da cultura camponesa, embora não seja suficiente para organizar as forças produtivas existentes no interior da familia, é fundamental para reestabelecer relações comunitárias e reivindicações politicas.

Em terceiro lugar, a diferenciação dos conteúdos culturais e comunitários dos camponeses não é uma imposição da sociedade, mas resulta de um processo que proporciona formas de pensar, agir e reagir determinadas pelas formas de produção individual e, portanto, pelo modo político de se organizarem, no lugar. 
A comunidade é, assim, recuperada como força política do lugar, que assume, interna e externamente, a familia camponesa como um poder de representação, organização e reeinvidicação. Nessa condição, a comunidade torna-se capaz de mediar a solução dos problemas de existência camponesa em várias esferas do processo produtivo.

Embora esteja considerando os processos de transformação dos modos de vida dos camponeses e, neste propósito não procure enxergar apenas elementos das comunidades tradicionais, compreendo que a existência das comunidades camponesas do cerrado mineiro é mais complexa do que se imagina. Elas têm resistido, historicamente, a pressões sucessivas de modos de produção e das várias instâncias da sociedade. Isso tudo implica identificarmos e analisarmos as múltiplas determinações sociais, políticas e culturais que também participam do processo de (re) existência camponesa.

\section{Referências}

BOURDIN, Alain. A questão local; tradução de Orlando dos Santos Reis. Rio de Janeiro: DP\&A, 2001

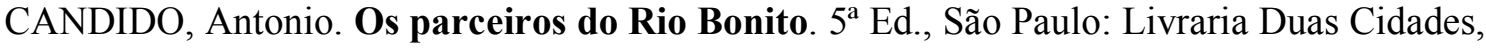
1979.

GRAZIANO da Silva J. Processo Técnico e Relações de Trabalho na Agricultura, São Paulo: Hucitec, 1981.

LEFEBVRE, Henri. A vida cotidiana no mundo moderno. São Paulo: Ed. Ática,1980.

KAUSTKY, Karl, A questão agrária. São Paulo: Proposta Editorial, 1968.

MARTINS, J. de S. Capitalismo e tradicionalismo. São Paulo: Pioneira, 1975

MARTINS, J. de S. O cativeiro da terra. São Paulo: Ciências Humanas, 1979.

MARTINS, J. de S. Expropriação e violência. São Paulo: Hucitec, 1980. 
SANDRONI, Paulo. A questão Agrária e o Campesinato. A "funcionalidade" da pequena produção Mercantil. São Paulo: Polis, 1980.

RAFFESTIN, Claude. Por uma Geografia do poder. São Paulo: Ática, 1993.

SANTOS, Milton. O espaço do cidadão. São Paulo: Nobel, 1987.

SANTOS, Milton. Metamorfoses do espaço habitado. São Paulo: Hucitec, 1988.

SANTOS, M. A Natureza do Espaço: técnica e tempo. Razão e emoção. $2^{\text {a }}$ Edição. São Paulo: Hucitec, 1997.

SANTOS, Rosselvelt José. Pesquisa empírica e trabalho de campo: algumas questões acerca do conhecimento geográfico. In: REVISTA SOCIEDADE \& NATUREZA. Ano 11, N. 21 e 22, Jan/Dez de 1999, p. 111-125.

SANTOS, Rosselvelt José. (Re) Ocupação do cerrado: novas gentes, outras identidades. In: ALMEIDA, M. Geralda, CHAVEIRO, Eguimar F. e BRAGA, Helaine. Geografia e cultura: os lugares da vida e a vida dos lugares (Org.). Goiânia: Editora Vieira, 2008, p. 47-74.

SANTOS, Rosselvelt J. Gaúchos e mineiros do Cerrado: metamorfoses das diferentes temporalidades e lógicas sociais. Uberlândia: EDUFU, 2008.

MARX, K. A miséria da filosofia. Porto: Publicações Escorpião, 1974.

MARX, K. O capital. São Paulo: Abril Cultural. vol. 1, 1985.

MÜLLER, G.. Estado, estrutura agrária e população. Petrópolis: Vozes, 1980.

PRADO Jr., C.. A questão agrária no Brasil. São Paulo: Brasiliense, 1979.

VELHO, O. G.. “A propósito de terra e Igreja”. Encontros com a civilização brasileira, 22. Rio de Janeiro: Civilização Brasileira, 1980 